\title{
CARACTERÍSTICAS COMERCIAIS DE ALFACE ROSABELA E ROBUSTA EM AMBIENTE COM MALHA FOTO CONVERSORA VERMELHA
}

\begin{abstract}
Rosandro Boligon Minuzzi ${ }^{1}$, Carolina do Amaral Frederico ${ }^{2}$, Rosangela Rodrigues dos Santos ${ }^{3}$
RESUMO - O objetivo deste estudo foi avaliar as características comerciais de duas cultivares de alface crespa em ambiente coberto com malha foto conversora vermelha (ChromatiNet Leno). O delineamento experimental foi em blocos casualizados em esquema fatorial $2 \times 2$ com tratamentos resultantes da combinação de duas cultivares (Robusta, tipo crespa verde e Rosabela, tipo crespa vermelha) e dois ambientes de cultivo (descoberto e coberto com malha), realizados em cinco diferentes ciclos (datas de cultivo). Foram avaliadas as seguintes variáveis obtidas das folhas sadias com comprimento maior que $4 \mathrm{~cm}$ de cada planta da área útil: número de folhas, massa fresca, área foliar e coloração (esta última somente para a cultivar Rosabela). No ambiente coberto com malha foto conversora a alface Robusta crespa verde teve maior crescimento das folhas e a Rosabela crespa vermelha maior ganho de massa fresca durante os meses mais frios e de menor fotoperíodo.
\end{abstract}

Palavras chave: ambiente protegido, área foliar, Lactuca sativa.

\section{COMMERCIAL CHARACTERISTICS OF ROSABELA AND ROBUSTA LETTUCE IN ENVIRONMENT WITH RED SHADING NET}

\begin{abstract}
The objective of this study was to evaluate the commercial characteristics of two cultivars lettuce in an environment covered with red shading net (ChromatiNet Leno). The experimental design was a randomized complete block design in a $2 \times 2$ factorial scheme with treatments resulting from the combination of two cultivars (Robusta green and Rosabela red) and two cultivation environments (uncovered and covered with shading), carried out in five different cycles (dates of sowing). The following variables were obtained from healthy leaves with length greater than $4 \mathrm{~cm}$ of each plant of the useful area: leaf number, fresh mass, leaf area and color (it's only Rosabela cultivar). In the environment covered with red shading the green Robusta lettuce had greater growth of the leaves and Rosabela red greater gain of fresh mass during the cooler months and of smaller photoperiod.
\end{abstract}

Keywords:greenhouse, leaf area, Lactuca sativa.

\section{INTRODUÇÃO}

O cultivo protegido de hortaliças recebeu grande impulso no Brasil entre o final dos anos 1980 e início da década seguinte. A tecnologia do cultivo protegido alia-se às novas tecnologias empregadas na agricultura, com a finalidade de buscar respostas ao desafio de produzir alimentos de maneira competitiva e sustentável, elevando a produtividade e qualidade dos produtos e, assim, diminuindo os riscos e as incertezas do setor agrícola (Darezzo et al., 2004).

Dentre as plantas mais cultivadas em ambiente protegido, destaca-se a alface (Lactuca sativa). É uma das hortaliças folhosas mais presentes na mesa dos brasileiros, sendo considerada a mais popular folhosa

${ }^{1}$ Professor do Departamento de Engenharia Rural, Universidade Federal de Santa Catarina, Av. Admar Gonzaga, 1346, Itacorubi, 88034-001, Florianópolis, SC.rosandro.minuzzi@ufsc.br

${ }^{2}$ Graduanda em Agronomia, Universidade Federal de Santa Catarina, Av. Admar Gonzaga, 1346, Itacorubi, 88034-001, Florianópolis, SC. carolinafrederico32@hotmail.com

${ }^{3}$ Graduanda em Agronomia, Universidade Federal de Santa Catarina, Rod. Ulysses Gaboardi, km 3, 89520-000, Curitibanos, SC.eng.rosangela@bol.com.br 
(Lopes et al., 2010). Apresenta cerca de 75 cultivares comerciais, que exploram diferenças nos formatos, tamanhos e cores das plantas.

Atualmente, o mercado apresenta uma grande variedade de malhas para diferentes fins, como as malhas foto conversoras que visam principalmente aumentar a eficiência fotossintética da cultura pela modificação do espectro da luz solar, além de minimizar os danos causados pelo excesso de radiação solar e evitar danos causados por granizo, pássaros, insetos e chuvas fortes. A duração da exposição, a qualidade e a intensidade de luz modificam as características de qualidade, tais como coloração, espessura da casca, tamanho, teor de sólidos solúveis, de vitamina $\mathrm{C}$ e a massa das frutas e hortaliças, que dependem da fotossíntese para serem produzidas (Chitarra \& Chitarra, 2005).

Moreira (2001) destaca que a fotossíntese ocorre eficientemente com a luz azul ( $400-430 \mathrm{~nm})$ e a com a luz vermelha ( 600 - $730 \mathrm{~nm}$ ) que são captadas pelos pigmentos do cloroplasto. Especifica que a reação da planta ao vermelho estimula o crescimento heterotrófico que promove um alto grau de crescimento vegetativo e aumento na síntese da antocianina, que são pigmentos responsáveis por uma grande variedade de cores das frutas, flores e folhas.

Para se cultivar hortaliças como alface, em ambiente protegido, é necessário conhecer muito bem as necessidades fisiológicas das diversas variedades, as condições microclimáticas e suas variações no decorrer do ano no ambiente em que serão cultivadas. Diante do exposto, questiona-se como seria o desempenho de uma hortaliça coberta com malha foto conversora em uma região com as quatro estações do ano bem definidas, isto é, com grande variabilidade climática durante o ano.

Assim, o objetivo deste estudo foi avaliar as características comerciais de duas cultivares de alface do tipo crespa em ambiente coberto com malha foto conversora (ChromatiNet Leno) para regiões com clima semelhante ao de Florianópolis, no estado de Santa Catarina.

\section{MATERIALE MÉTODOS}

O experimento foi conduzido no Centro de Ciências Agrárias, da Universidade Federal de Santa Catarina, no município de Florianópolis-SC (latitude: -27,57², longitude: $-48,50^{\circ}$ e altitude de 5 metros). As plantas foram cultivadas em vasos plásticos de 3,6 litros utilizando o solo da área (classe Neossolo Quartzarênico). O clima do local de acordo com a classificação climática de Köppen é do tipo subtropical constantemente úmido, sem estação seca e com verão quente. O fotoperíodo varia de 13,8 h (dezembro) a 10,2 h (junho) e a temperatura média do ar de $25,2^{\circ} \mathrm{C}$ (fevereiro) a $16,4^{\circ} \mathrm{C}$ (julho).

O delineamento experimental foi em blocos casualizados em esquema fatorial $2 \times 2$ com tratamentos resultantes da combinação de duas cultivares (Robusta, tipo crespa verde e Rosabela, tipo crespa vermelha) e dois ambientes de cultivo (descoberto e coberto com malha), realizados em cinco diferentes ciclos (datas de cultivo). No ambiente coberto foi utilizada a malha foto conversora vermelha (ChromatiNet Leno), cobrindo totalmente a área da parcela a 1,5 metros de altura.

As mudas foram preparadas em bandejas de poliestireno expandido (isopor ${ }^{\circledR}$ ) com 128 células, preenchidas com o mesmo solo utilizado nos vasos e com sementes tratadas. O transplante das mudas para os vasos foi realizado quando as mesmas atingiram de duas a três folhas definitivas, nas seguintes datas: 22/08/2015, 15/10/2015, 23/03/2016, 07/10/2016 e 03/ 02/2017.

As parcelas foram de 1,5 x 1,5 m com 36 plantas em espaçamento entre os vasos de forma que os seus centros ficassem a uma distância de 0,3 m entre si, sendo que para a área útil considerou-se as 16 plantas centrais (repetições) de cada parcela (oito para cada cultivar). Não foi feita nenhuma adubação de cobertura e quando necessário foi realizado arranque de ervas daninhas. As irrigações foram feitas igualmente de forma a sempre manter o elevado teor de umidade do solo, identificado pela presença de umidade na camada superficial das cultivares no ambiente de cultivo descoberto.

Foram avaliadas as seguintes variáveis obtidas das folhas sadias com comprimento maior que $4 \mathrm{~cm}$ de cada planta: número de folhas, massa fresca, área foliar e coloração (esta última somente para a cultivar Rosabela). Em cada folha foi medido o comprimento (C) e a sua maior largura (L) para o cálculo da área foliar (AF), conforme equação 1, proposta por Francis et al. (1969).

$$
\mathrm{AF}=\mathrm{C} \cdot \mathrm{L} \cdot 0,5
$$


O valor 0,5 é o fator de forma atribuído para a alface, obtido de forma semelhante por Francis et al. (1969) para a cana-de-açúcar. Assim, considerou-se que a área de uma folha de alface corresponde a 50\% da área retangular calculada, sugerindo o citado fator de forma utilizado na equação 1 .

Quanto a análise da coloração da cultivar Rosabela, tipo crespa vermelha, foram escolhidas aleatoriamente seis folhas representativas de cada planta da área útil (exceto da menor e maior planta de acordo com o diâmetro do disco foliar), sendo três folhas externas e três medianas, donde foram obtidas fotos digitais (Figura 1a). Em cada foto foi delimitado as áreas de acordo com quatro classes de cores (vermelho intenso, vermelho fraco, verde intenso e verde fraco - Figura 1b) utilizando o software CorelDraw X5 e na sequência a extensão Rainbow do Firefox para indicar o percentual de cada uma das classes de cores das seis folhas.

Considerou-se o momento da colheita quando pelo menos 75\% das plantas da área útil de ambos ambientes de cultivo de uma cultivar estavam com suas folhas tenras, antes do ponto de crescimento máximo e sem indícios de pendoamento (Henz et al., 2008).

A média das variáveis obtidas de cada planta da área útil dos tratamentos foram submetidas a análise de variância e comparadas estatisticamente ao nível de 5\% de significância pelo teste t Student, com o uso do software Past 3.0.

\section{RESULTADOS E DISCUSSÃO}

As duas cultivares de alface analisadas no estudo, tiveram respostas diferentes para área foliar e número de folhas nos dois ambientes (Tabela 1). Enquanto a Robusta teve uma maior área foliar no ambiente coberto $\left(76,3 \mathrm{~cm}^{2}\right)$ com a malha foto conversora leno vermelha, a Rosabela apresentou uma diferença significativa no número de folhas, sendo maior no ambiente descoberto do que no cultivo em ambiente coberto com a malha foto conversora.

Efeito distinto entre as cultivares nos dois ambientes foi observado na variabilidade das características comerciais analisadas. Enquanto a área foliar e a massa fresca da alface Robusta tiveram uma menor variabilidade no ambiente coberto em relação ao descoberto, com o número de folhas sadias por planta ocorreu o contrário. Já para a alface Rosabela, ocorreu exatamente o oposto para as três variáveis analisadas, isto é, no ambiente coberto com malha foto conversora leno vermelha a dispersão dos dados de área foliar e massa fresca foram maiores do que no cultivo em ambiente descoberto, mas não quanto ao número de folhas sadias por planta (Tabela 1).

Na alface Rosabela, o uso da malha foto conversora leno vermelha não surtiu efeito significativo na coloração das suas folhas (Tabela 2), apesar da malha alterar o metabolismo por aumentar a incidência de radiação nos comprimentos do vermelho (Oren-Shamir et al., 2001). Inserido neste contexto de alteração na qualidade/ quantidade de radiação e metabolismo de vegetais, Morais et al. (2011) não encontraram diferença na acidez titulável, vitamina C, clorofila total e pH da alface cultivar Olinda em sistema hidropônico, cultivadas em ambientes cobertos com malhas termorefletoras com diferentes percentuais de sombreamento. Os autores acreditam que não houve redução na taxa fotossintética, ocasionada
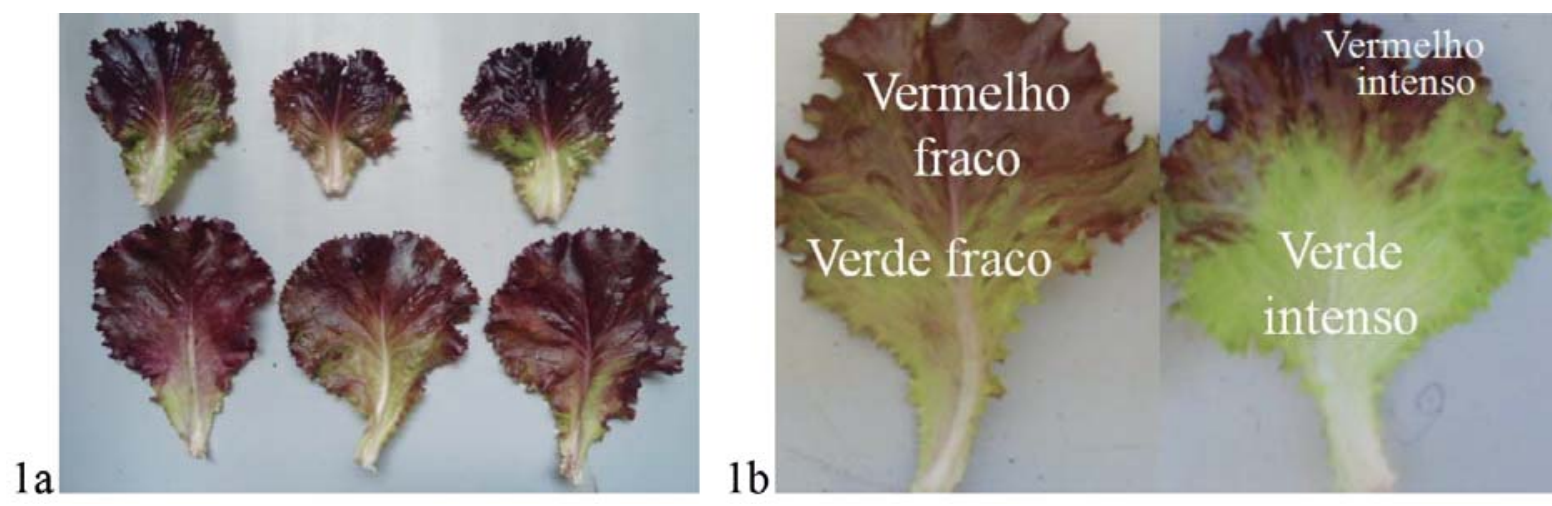

Figura 1 - Exemplo da escolha de seis folhas por planta (1a) e da classificação das cores utilizadas no estudo (1b) 
pelo sombreamento que comprometesse a síntese de ácidos e vitaminas na folha da alface. Quanto a coloração, Minuzzi et al. (2017) encontraram diferença nas tonalidades mais intensas do vermelho e verde da alface Rosabela cultivada em ambientes cobertos com três diferentes malhas.

O uso de um material como cobertura pode ter diferentes efeitos em uma cultura, em função das exigências fisiológicas da planta e o clima do local de cultivo. Pelas cinco safras deste estudo terem ocorrido em diferentes épocas do ano (condições climáticas distintas), a mesma análise feita com as características comerciais de ambas as cultivares de alface, foram realizadas reunindo as safras em dois grupos em função dos meses com temperatura do ar mais e menos elevada, com maior e menor luminosidade e intensidade de radiação solar. Desta forma, foi possível identificar mais variáveis significativamente diferentes entre os ambientes para a alface Robusta, mas mantendo a tendência que foi observada sem discriminar os cultivos em diferentes épocas do ano.

Durante os meses mais quentes do ano observase que a alface Robusta teve uma maior área foliar e massa fresca quando cultivada em ambiente coberto com malha leno vermelha (Tabela 3). Já nos meses mais frios, a massa fresca da Rosabela $(105,5 \mathrm{~g})$ e a área foliar da Robusta $\left(72 \mathrm{~cm}^{2}\right)$ foram maiores no ambiente coberto com malha foto conversora. Ressaltase a pequena variação na área foliar das plantas cultivadas no ambiente coberto para ambas as cultivares (Tabela 4). Radin et al. (2004) explicam que em regiões ou períodos do ano com maior temperatura do ar e radiação solar, o maior sombreamento devido ao uso de malhas reduz o efeito de fotoinibição na alface, promovendo produção de folhas maiores, o que contribui para maior quantidade de massa fresca por planta e que, segundo Puiatti \& Finger (2005), diminui o tecido paliçádico e aumenta o lacunoso, resultando numa maior área foliar específica.

A complexidade e importância em estudos com diferentes malhas, culturas, regiões e épocas do ano é apresentado por Otto et al. (2013). Os pesquisadores realizaram estudo com duas cultivares de alface americana em diferentes ambientes de cultivo e épocas do ano. No inverno, as plantas cultivadas em ambiente coberto com agrotêxtil branco direto e em túnel baixo com polietileno transparente apresentaram fitomassa fresca da cabeça comercial semelhante ao ambiente descoberto no final do ciclo, mas superiores as plantas cultivadas em ambiente com ChromatiNet vermelha e com AlumiNet.

Apesar do uso de malhas representarem uma redução no fluxo de luz a níveis inadequados, durante os meses mais quentes no sul do Brasil não é prejudicial pelo

Tabela 1 - Área foliar (AF), massa fresca (MF) e número de folhas sadias das alfaces Robusta e Rosabela em ambiente descoberto e coberto com malha foto conversora leno vermelha

\begin{tabular}{lllllll}
\hline & \multicolumn{3}{c}{ Robusta crespa verde } & \multicolumn{3}{c}{ Rosabela crespa vermelha } \\
\hline Item & AF $\left(\mathrm{cm}^{2}\right)$ & MF $(\mathrm{g})$ & $\mathrm{N}^{\circ}$ Folhas & AF $\left(\mathrm{cm}^{2}\right)$ & MF (g) & $\mathrm{N}^{\circ}$ Folhas \\
Coberta & $76,3 \mathrm{a}$ & $73,8 \mathrm{a}$ & $19,7 \mathrm{a}$ & $78,2 \mathrm{a}$ & $81,4 \mathrm{a}$ & $19,3 \mathrm{a}$ \\
CV (\%) & 19 & 33 & 19 & 26 & 35 & 16 \\
Descoberta & $55,5 \mathrm{~b}$ & $68,1 \mathrm{a}$ & $20,4 \mathrm{a}$ & $68,8 \mathrm{a}$ & $80,8 \mathrm{a}$ & $21,8 \mathrm{~b}$ \\
CV (\%) & 28 & 47 & 13 & 19 & 27 & 18 \\
\hline
\end{tabular}

"Médias com letras diferentes nas colunas diferem estatisticamente entre si pelo teste $t$ Student $(\mathrm{P}<0,05)$.

Tabela 2 - Percentual de ocorrência de quatro classes de cores nas folhas de alface Rosabela, tipo crespa vermelha em ambiente descoberto e coberto com malha foto conversora leno vermelha

\begin{tabular}{lcccc}
\hline Item & Vermelho intenso & Vermelho fraco & Verde intenso & Verde fraco \\
\hline Coberto & 20,1 a & 32,8 a & 31,5 a & 13,5 a \\
Descoberto & 27,3 a & 30,5 a & 32,2 a & 9,9 a \\
\hline
\end{tabular}

${ }^{*}$ Médias com letras diferentes nas colunas diferem estatisticamente entre si pelo teste $t$ Student $(\mathrm{P}<0,05)$. 
Tabela 3 - Área foliar (AF), massa fresca (MF) e número de folhas sadias das alfaces Robusta e Rosabela obtidas nos cultivos durante os meses mais quentes e de maior luminosidade em ambiente descoberto e coberto com malha foto conversora leno vermelha

\begin{tabular}{llccccc}
\hline & & Robusta crespa verde & \multicolumn{3}{c}{ Rosabela crespa vermelha } \\
\hline Item & AF $\left(\mathrm{cm}^{2}\right)$ & MF $(\mathrm{g})$ & $\mathrm{N}^{\circ}$ Folhas & $\mathrm{AF}\left(\mathrm{cm}^{2}\right)$ & MF (g) & $\mathrm{N}^{\circ}$ Folhas \\
Coberta & $77,7 \mathrm{a}$ & $66,3 \mathrm{a}$ & $21,2 \mathrm{a}$ & $81,3 \mathrm{a}$ & $65,3 \mathrm{a}$ & $19,8 \mathrm{a}$ \\
CV (\%) & 21 & 21 & 14 & 28 & 32 & 18 \\
Descoberta & $54,7 \mathrm{~b}$ & $47,0 \mathrm{~b}$ & $20,2 \mathrm{a}$ & $71,3 \mathrm{a}$ & $78,3 \mathrm{a}$ & $23,4 \mathrm{~b}$ \\
CV $(\%)$ & 33 & 28 & 12 & 19 & 31 & 18 \\
\hline
\end{tabular}

${ }^{*}$ Médias com letras diferentes nas colunas diferem estatisticamente entre si pelo teste t Student $(\mathrm{P}<0,05)$.

Tabela 4 - Área foliar (AF), massa fresca (MF) e número de folhas sadias das alfaces Robusta e Rosabela obtidas nos cultivos durante os meses mais frios e de menor luminosidade em ambiente descoberto e coberto com malha foto conversora leno vermelha

\begin{tabular}{|c|c|c|c|c|c|c|}
\hline \multirow[b]{2}{*}{ Item } & \multicolumn{3}{|c|}{ Robusta crespa verde } & \multicolumn{3}{|c|}{ Rosabela crespa vermelha } \\
\hline & $\mathrm{AF}\left(\mathrm{cm}^{2}\right)$ & MF (g) & $\mathrm{N}^{\circ}$ Folhas & $\mathrm{AF}\left(\mathrm{cm}^{2}\right)$ & MF (g) & $\mathrm{N}^{\circ}$ Folhas \\
\hline Coberta & 72,0 a & 85,0 a & 17,6 a & 68,8 a & 105,5 a & 18,4 a \\
\hline CV (\%) & 3 & 38 & 21 & 6 & 19 & 12 \\
\hline Descoberta & 57,7 b & 99,7 а & $20,6 \mathrm{~b}$ & 61,2 a & 84,5 b & 19,4 a \\
\hline $\mathrm{CV}(\%)$ & 10 & 26 & 14 & 14 & 20 & 11 \\
\hline
\end{tabular}

${ }^{*}$ Médias com letras diferentes nas colunas diferem estatisticamente entre si pelo teste t Student $(\mathrm{P}<0,05)$.

maior fotoperíodo e radiação solar, além de, minimizar o aquecimento do solo e consequente evaporação. Mesmo não havendo medições, foi visível no ambiente coberto com malha a maior umidade do solo, sendo uma justificativa plausível para a maior área foliar e massa fresca encontrada para a Robusta crespa verde, mesmo que a irrigação tenha ocorrido de forma igual entre os tratamentos. Com isso, resultaria numa maior produtividade da Robusta crespa verde, como o obtido nos estudos de Bezerra Neto et al. (2005) e Queiroga (2000).

Utilizando a cultivar de alface Great Lakes, Bezzera Neto et al. (2005) encontraram maior produtividade nos ambientes com malhas preta, branca e verde, do que em relação ao cultivo em ambiente descoberto na quente região de Mossoró-RN. Para esta mesma cultivar Queiroga (2000) avaliando o efeito de tipos de tela de sombreamento em cultivares de alface observou que a tela branca proporcionou ganho de produtividade de $27 \%$ em relação à alface sem sombreamento. Também foram observadas maiores rendas bruta e líquida e uma maior taxa de retorno com tela branca.

\section{CONCLUSÕES}

A alface Robusta crespa verde teve maior crescimento das folhas em ambiente coberto com malha foto conversora vermelha, principalmente nos meses mais quentes.

O ambiente com malha foto conversora vermelha somente favoreceu o ganho de massa fresca da alface Rosabela crespa vermelha durante os meses mais frios e de menor fotoperíodo.

\section{LITERATURA CITADA}

BEZERRA NETO, F.; ROCHA, R.C.C.; NEGREIROS, M.Z. et al. Produtividade de alface em função de condições de sombreamento e temperatura e luminosidade elevadas.

Horticultura Brasileira, Brasília, v.23, n.2, p.189-192, 2005.

CHITARRA M.I.F.; CHITARRA, A.B. Póscolheita de frutos e hortaliças:

fisiologia e manuseio. $2^{a}$ ed., Lavras, MG: Ed. UFLA, 2005. 785p. 
DAREZZO, R.J.; AGUIAR, R.L.; AGUILERA, G.A.H. et al. Cultivo em ambiente protegido: histórico, tecnologias e perspectivas. Viçosa, MG: Ed. UFV, 2004. 332p.

FRANCIS, C.A.; RUTGER, J.N.; PALMER, A.F.E. A rapid method for plant leaf area estimation in maize (Zea mays L). Crop Science, v.9, p.537539, 1969.

HENZ, G.P.; CALBO, A.G.; MALDONADE, I.R. Manuseio pós-colheita da alface. Brasília, DF: Ed. Embrapa, 2008. 12p.

LOPES, C.A.; QUESADO-DUVAL, A.M.; REIS, A. Doenças da alface. Brasília, DF: Embrapa Hortaliças, 2010. 68p.

MINUZZI, R.B.; FREDERICO, C.A.; SANTOS, R.R. Características comerciais da alface Rosabela em ambientes cobertos com diferentes telas. In: ENCONTRO SUL BRASILEIRO DE METEOROLOGIA, 8., 2017. Anais... Pelotas: UFPel, 2017.

MORAIS, P.L.D.; DIAS, N.S.; ALMEIDA, M.L.B. et al. Qualidade pós-colheita da alface hidropônica em ambiente protegido sob malhas termorefletoras e negra. Revista Ceres, v.58, n.5, p.638-644, 2011.
MOREIRA, M.A. Fundamentos do sensoriamento remoto e metodologias de aplicação. São José dos Campos: INPE, 2001. 250p.

OREN-SHAMIR, M.; GUSSAKOVSKY, E.E.; SHPIEGEL, E. et al. Coloured shade nets can improve the yield and quality of green decorative branches of Pittosphorum variegatum. Journal of Horticultural Science and Biotechnology, v.76, n.3, p.353-361, 2001.

OTTO, R.F.; NIESING, P.C.; CORTEZ, M.G. et al. Microclimatic modifications and productive responses of the Iceberg lettuce (Lactuca sativa) in protected environments. Revista Ciência Agronômica, v.44, n.4, p.878-884, 2013.

PUIATTI, M.; FINGER, F.L. Fatores climáticos. In: FONTES, P.C.R. Olericultura: teoria e prática. Viçosa: Ed. UFV, 2005. p.17 30.

QUEIROGA, R.C.F. Produção de alface em função de cultivares e tipos de tela de sombreamento nas condições de Mossoró - RN. Dissertação (Mestrado em Fitotecnia). Mossoró, RN: ESAM, 2000. 78p.

RADIN, B.; REISSER JÚNIOR, C.; MATZENAUER, R. et al. Crescimento de cultivares de alface conduzidas em estufa e a campo. Horticultura Brasileira, v.22, p.178 181, 2004.

Recebido para publicação em 05/7/2017 e aprovado em 08/11/2017. 